\title{
Interaction of Tetracapsuloides bryosalmonae, the causative agent of proliferative kidney disease, with host proteins in the kidney of Salmo trutta
}

\author{
Gokhlesh Kumar • Michael Gotesman • \\ Mansour El-Matbouli
}

Received: 26 November 2014 / Accepted: 22 January 2015 / Published online: 7 February 2015

(C) The Author(s) 2015. This article is published with open access at Springerlink.com

\begin{abstract}
Tetracapsuloides bryosalmonae (Myxozoa) is the causative agent of proliferative kidney disease in various species of salmonids which are found in Europe and North America. Less information about the interactions of T. bryosalmonae proteins with salmonid proteins during parasite development is known. In this study, antiT. bryosalmonae monoclonal antibody-linked to $N$ hydroxysuccinimide-activated spin columns were used to purify parasite and host proteins from the kidneys of infected and non-infected brown trout (Salmo trutta) Linnaeus, 1758. The samples were next analyzed by electrospray ionization coupled to mass spectrometry to identify proteins that may be involved in the infection and proliferation of T. bryosalmonae within the brown trout host. A total of 6 parasite proteins and 40 different host proteins were identified in this analysis. The identified host proteins function in various processes, which include host defense, enzymatic, and structural components. In conjunction with modern molecular based tools, such siRNA, gene replacement, or gene disruption, this data can ultimately be used to develop novel control methods for T. bryosalmonae, based on the proteins or pathways identified in this study.
\end{abstract}

Keywords Salmonids $\cdot$ Myxozoa $\cdot$ Proliferative kidney disease $\cdot$ Protein interaction $\cdot$ Electrospray ionization mass spectrometry

G. Kumar • M. Gotesman • M. El-Matbouli $(\bowtie)$

Clinical Division of Fish Medicine, Department for Farm Animals and Veterinary Public Health, University of Veterinary Medicine, Veterinärplatz 1, 1210 Vienna, Austria

e-mail: mansour.el-matbouli@vetmeduni.ac.at

\section{Introduction}

Tetracapsuloides bryosalmonae belongs to the phylum Myxozoa, class Malacosporea, and causes proliferative kidney disease (PKD) in various species of salmonids (Anderson et al. 1999). This parasite is found in Europe and North America and can lead to severe losses in rainbow trout (Oncorhynchus mykiss) Walbaum, 1792, and brown trout (Salmo trutta) Linnaeus, 1758; farms and the associated economic impact of this disease makes it an important factor for aquaculture (ElMatbouli and Hoffmann 2002). Additionally, PKD is suspected of contributing to the decline of wild brown trout and salmon populations, especially in Switzerland (Wahli et al. 2002). Spores develop in the kidney tubules of infected fish and are released via urine to infect freshwater bryozoans (Morris and Adams 2006, 2007; Grabner and El-Matbouli 2008). Proliferation of T. bryosalmonae induces granulomatous cellular response in the interstitial tissue which induces swelling of the kidney and spleen (Clifton-Hadley and Feist 1989).

Knowledge about protein interactions may be used to understand how parasites enter host cells and the process of parasite development during infection and help explain the selectivity of the parasite for the targeted tissue. However, very little is known about the interactions of T. bryosalmonae proteins with salmonid proteins during parasite entry or development. Protein purification using antibody-based methods can be used to study in vivo protein interactions (Tuxworth et al. 2005; Gotesman et al. 2011). Mass spectrometry has become a standard protocol in the identification of proteins and has become favored over the classical Edman degradation method (Cameron 2012). Electrospray ionization mass spectrometry (ESI-MS) is a highly sensitive form of MS used in the detection of samples that are at femtomolar concentrations in nanomole quantities (Ho et al. 2003). Recently, antibody- 
based protein purification followed ESI-MS was used to investigate Cyprinid herpesvirus 3 (CyHV-3) and host interactions in common carp (Cyprinus carpio) and identified several host defense proteins that may interact with CyHV-3 (Gotesman et al. 2013).

The objective of this study was to identify parasite and host protein interactions for T. bryosalmonae in the kidney of brown trout host by antibody-based protein purification followed by ESI-MS. The method of choice for this study was the use of antibody-based protein purification followed by ESI-MS to identify parasite-host protein interactions. From the identification of proteins in this study, there is an improvement in our understanding of parasite development in brown trout, and the identified proteins could potentially serve as targets for control of PKD in salmonids.

\section{Materials and methods}

\section{Fish samples}

Fish used for the present study originated from a previous experiment. Details of the experimental design and sampling procedure have been provided previously (Kumar et al. 2013, 2014, 2015). Briefly, brown trout were infected with free spores of T. bryosalmonae and maintained under laboratory conditions. Posterior kidneys were sampled from fish at different time points and tested for the presence of T. bryosalmonae by real-time PCR (qRT-PCR) and immunohistology using anti-T. bryosalmonae monoclonal antibody (MAB) P01 (Kumar et al. 2013).

\section{Tissue lysate preparation}

Kidney samples $(n=8)$ collected at $8-10$ weeks post exposure (wpe) were homogenized in a 1:1 ratio with a non-denaturing lysis buffer: $50 \mathrm{mM}$ Tris- $\mathrm{HCl}(\mathrm{pH} 8.0), 150 \mathrm{mM}, \mathrm{NaCl}$, $20 \mathrm{mM}$ ethylene diamine tetraacetic acid, $1 \% \mathrm{Na}-$ deoxycholate, $1 \%$ Triton X-100 (Williams 2000), and protease inhibitor cocktail (100 $\mu \mathrm{l}$ inhibitor/ml of lysis buffer). Subsequently, lysate was vigorously vortexed and centrifuged at $14,000 \mathrm{~g}$ for $15 \mathrm{~min}$. The supernatant was transferred to a sterile $1.5-\mathrm{mL}$ tubes and re-centrifuged at $14,000 \mathrm{~g}$ for an additional $15 \mathrm{~min}$. Supernatant from the second centrifugation for each fraction was separately used for affinity purification as described in the following sections.

\section{Western blotting}

Western blot analysis was used to test specificity of antiT. bryosalmonae MAB P01 (Aquatic Diagnostics Ltd) in both infected and non-infected kidney supernatant protein samples. Briefly, supernatant proteins were separated by electrophoresis on $12 \%$ SDS-PAGE gel, and then proteins were transferred onto polyvinylidene difluoride membrane. The membrane was blocked, incubated with antiT. bryosalmonae MAB, and later incubated with goat antimouse IgG HRP conjugate. After washing, the reactivity of antibody was confirmed by colorimetric detection using an Opti-4CN substrate (BIO-RAD).

Preparation of monoclonal antibody-linked spin columns

Monoclonal antibody IgG1 isotype against $T$. bryosalmonae P01 was conjugated to $N$-hydroxysuccinimide-activated 33mg-capacity agarose spin column according to the manufacturer's instructions. T. bryosalmonae MABs recognize parasite surface antigens and bind to both extrasporogonic and sporogonic stages of parasite (Marin de Mateo et al. 1996). Anti-T. bryosalmonae MAB $(200 \mu \mathrm{g})$ was resuspended into 400- $\mu$ l phosphate-buffered saline (PBS) at $\mathrm{pH} 7.4$ and incubated in agarose spin column overnight at $4{ }^{\circ} \mathrm{C}$ with mild shaking of $300 \mathrm{rpm}$ in an Eppendorf Thermomixer Comfort. The spin columns were emptied and washed twice with PBS after overnight incubation. Subsequently, the spin columns were quenched with $1 \mathrm{M}$ ethanolamine, $\mathrm{pH} 7.4$, by incubation for $1 \mathrm{~h}$ at $12{ }^{\circ} \mathrm{C}$ with mild shaking. Finally, the spin columns were emptied by centrifugation and washed six times with PBS.

\section{Protein purification}

Non-denatured tissue extracts from T. bryosalmonae infected and non-infected kidneys samples were separately incubated overnight at $12{ }^{\circ} \mathrm{C}$ with mild shaking at $300 \mathrm{rpm}$ in monoclonal antibody-linked spin columns (previously described). Additionally, control spin columns (with or without antibody) were used to test for unspecific binding of proteins. The spin columns were washed three additional times after the flow of the washes was 0 at optical density at $280\left(\mathrm{OD}_{280}\right)$, for a total of eight washes with PBS. The spin columns were subsequently eluted with $0.1 \mathrm{M}$ glycine, $\mathrm{pH} 3.0$, by incubation with mild shaking for $1 \mathrm{~h}$ at $12{ }^{\circ} \mathrm{C}$, and the $\mathrm{pH}$ was neutralized by addition of $1 \mathrm{M}$ Tris base, $\mathrm{pH}$ 8.0. The columns were next washed with PBS and eluted. Eluted fractions were concentrated using a dry vacuum concentrator.

\section{ESI-MS analysis}

The samples, which consisted of the entire antibody-purified products originating from either infected or non-infected fish, were also separately analyzed by ESI-MS. In-solution digest using trypsin was performed for each sample. The resulting peptides were analyzed by LC-MS/MS using a nanoHPLC system coupled with the ion trap mass spectrometer. The instrument's software was used to handle data acquisition and 
data processing. Peptides were searched with the mascot search engine (http://www.matrixscience.com) using proteins of fish, mammals, or myxozoan parasites in the NCBInr, UniProt, and Swiss-Prot and dbEST databases to identify proteins. The following parameters were used: enzyme trypsin, fixed modifications carbamidomethyl $(\mathrm{C})$, variable modifications deamidation (NQ) and oxidation (M), peptide mass tolerance $5 \mathrm{ppm}$, fragment mass tolerance $0.4 \mathrm{Da}$, and with one missed cleavage site allowed. Proteins that have at least two unique peptides with a significant score $(P<0.01)$ and ion score cut-off of 20 in the mascot search were considered for protein identification. Electrospray ionization mass spectrometry analysis was performed by the DKFZ, The German Cancer Research Centre, Heidelberg, Germany.

\section{Results}

\section{Western blotting}

In Western blotting, anti-T. bryosalmonae MAB detected differ blotting profiles in the kidney supernatants of infected brown trout. The differences were for major and minor protein bands in the kidney supernatants of infected brown trout and few protein bands in non-infected kidney (Fig. 1).

\section{ESI-MS analysis}

A total of 6 parasite proteins and 40 different host proteins were identified in this analysis. The parasite proteins identified consisted of several structural proteins, such as actin and histones as well an enzymatic protein termed glyceraldehyde-3-

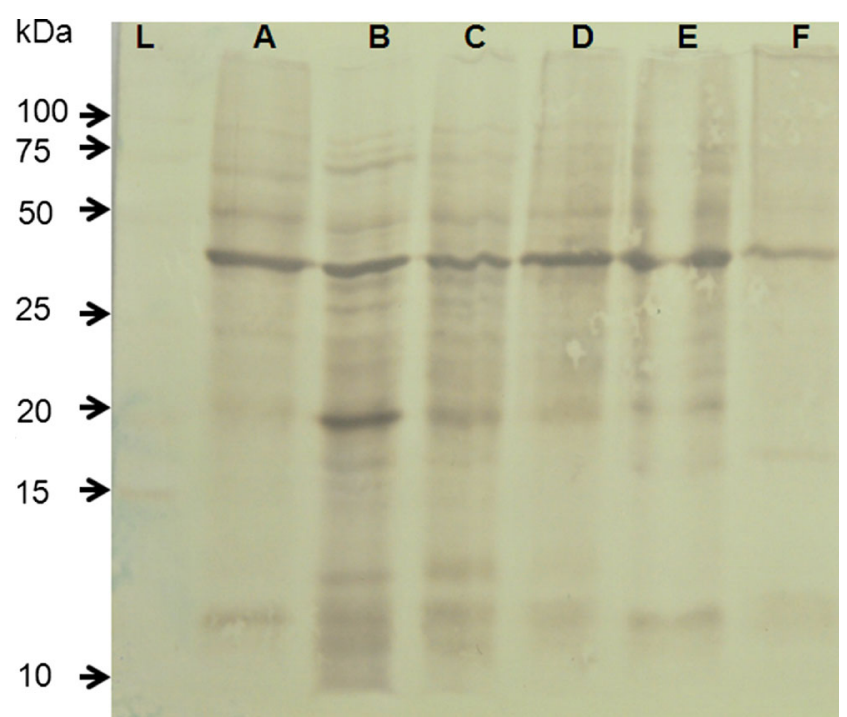

Fig. 1 Western blot analysis of supernatant proteins from infected and non-infected kidneys of brown trout, Salmo trutta. Lanes $A-E$, supernatant proteins from infected kidney; lane $F$, supernatant proteins from non-infected kidney phosphate dehydrogenase (G3DPH) and a small nuclear ribonuclear protein (Table 1). Of the 30 host proteins identified in the kidney of brown trout infected with T. bryosalmonae, 6 were also identified in the kidney of non-infected brown trout (Table 2) and the other 24 were unique to the infected brown trout (Table 3). Similarly, of 10 proteins identified in the kidney of non-infected brown trout, 4 were unique to non-infected brown trout (Table 3).

\section{Discussion}

Parasite antigens are expressed and released into the host tissue during the sporogonic stages of the myxozoan parasite (Morris et al. 2004). Numerous intra-luminal sporogonic stages of T. bryosalmonae (Fig. 2a) were observed in the kidney of brown trout at 8-10 wpe along with low presporogonic stages using immunohistological examination (Kumar et al. 2013). However, little is known about how the pathogen enters and proliferates inside the brown trout. Understanding host-pathogen interactions can be helpful to further elucidate the pathogenesis and proliferation of T. bryosalmonae within the salmonid host. For this study, antibody-based purification followed by ESI-MS was used to explore the protein interactions of T. bryosalmonae proteins with brown trout proteins during the developmental stages of the parasite. The antigen for the commercially available antiT. bryosalmonae MAB P01 used in this study is unknown and also has not been fully characterized.

Of the 24 unique host proteins identified in the infected kidney sample, several have catalytic properties, such as transglutaminase E3, Xaa-Pro aminopeptidase, serine protease, and cationic trypsinogen. Some of the eclectic proteins include epiplakin which has been shown to have autoimmunogenic properties in humans (Fujiwara et al. 2001). Hemoglobin is the iron-containing oxygen-transport metalloprotein in erythrocytes (McMorrow et al. 1996). We found downregulation of hemoglobin in the kidney of infected brown trout (Kumar et al. 2014), which suggests that erythropoiesis was suppressed in the kidney. On the other hand, 26S protease regulatory subunit was upregulated in the kidney of infected brown trout (own unpublished data). Protein NODlike receptor $\mathrm{C} 3$ is an intra-cellular protein that plays a role in the immune system and activation of $\mathrm{T}$ cells (Conti et al. 2005). The activation of $T$ cells has been observed in the kidney of rainbow trout infected with $T$. bryosalmonae (Gorgoglione et al. 2013). Other important proteins, such as 14-3-3 and protein S100A9, were shown to be involved in either parasite or virus-host interactions in gilthead sea bream (Sparus aurata) and common carp, respectively (Davey et al. 2011; Ouyang et al. 2013). The 14-3-3 proteins are a family of conserved regulatory molecules that regulate a large spectrum of signaling pathways. The expression of 14-3-3 protein was 
Table 1 Malacosporean parasite proteins identified in the kidneys of brown trout infected with Tetracapsuloides bryosalmonae

\begin{tabular}{llcccc}
\hline Protein description & Accession number & Mass (Da) & Score & Matches & Coverage (\%) \\
\hline Actin & gi|148491610 & 31449 & 90 & 6 & 18.7 \\
Histone H3 & gi|148491585 & 18822 & 84 & 6 & 9.4 \\
Histone H2B & gi|148491596 & 18828 & 25 & 2 & 5.1 \\
Hypothetical protein & gi|148491565 & 17407 & 28 & 2 & 5.7 \\
Glyceraldehyde-3-phosphate dehydrogenase & gi|148492233 & 34089 & 24 & 2 & 2.2 \\
Small nuclear ribonucleoprotein D1 polypeptide 16 kDa & gi|148491909 & 32913 & 29 & 2 & 1.7 \\
\hline
\end{tabular}

downregulated in the head kidney of gilthead sea bream that was infected with myxozoan parasite, Enteromyxum leei (Davey et al. 2011). The aforementioned study suggests that the infection of T. bryosalmonae reduces the activities of signaling pathways that are essential for the induction of the brown trout immune system against parasite infection. S100A9, which is also known as migration inhibitory factorrelated protein 14 , is a calcium- and zinc-binding protein, and S100A9 plays a prominent role in the regulation of inflammatory processes and immune response of the host (Croce et al. 2009). The downregulation of S100A9 was observed in the head kidney of gilthead sea bream infected with $E$. leei by using microarray analysis (Davey et al. 2011). Therefore, the downregulation of S100A9 reduces inflammation in the kidney of infected brown trout and thereby supports developmental stages of $T$. bryosalmonae. These observations are in concordance with PKD signs in our previous study, in which we showed that the kidneys of rainbow trout, but not brown trout, were intensely swollen during parasite development (Kumar et al. 2013).

Six host proteins were identified in both infected and noninfected kidney samples (Table 2). Of the two enzymatic proteins identified, G3DPH and high choriolytic enzyme 1. G3DPH plays an important role in glycolysis and gluconeogenesis, and a major link between carbohydrate and lipid metabolisms (Ou et al. 2006). It is implicated in certain human neurological diseases such as Huntington's, Alzheimer's, and Parkinson's diseases (Tatton et al. 2003). G3DPH is downregulated in the head kidney of gilthead sea bream infected with E. leei, suggesting that glycolysis and related metabolic pathways were affected in the kidney of fish during parasitic infection and may associate with the disease of myxozoan parasite. High choriolytic enzyme 1 precursor, activated high choriolytic enzyme 1 precursor, is a hatching enzyme that exhibits choriolysis and proteolysis activities in Japanese rice fish (Oryzias latipes) (Yasumasu et al. 1989). Additionally, of the six malacosporean parasite proteins identified in this study, the presence of histones and small nuclear ribonucleoprotein indicates that the parasite is continuously managing transcription during development (Baer and Rhodes 1983).

Because overlapping proteins were eluted in both the infected and non-infected samples, this suggests that the antibody may cross-react with some host proteins as seen in the Western blot analysis (Fig. 1). In previous immunohistological studies, this antibody binds specifically to unknown antigen expressed on the surface of T. bryosalmonae (Marin de Mateo et al. 1996), and also the exact nature of this cross-reaction in both Western blot and antibody-based purification is unknown. Additionally, identified proteins that were unique to non-infected tissue may be have been outcompeted from interacting with the antibody or may have been downregulated in infected tissue and therefore not detected in samples originating from infected tissue samples. A detailed study in the future would help to understand the cross-reaction of antibody and the nature of parasite antigen.

In conclusions, we identified host-parasite protein interactions for the proliferative kidney disease and serves as an explorative method that can be used in conjunction with qRT-PCR and microarray-based techniques to identify

Table 2 Overlapping host proteins identified in the kidneys of both infected and non-infected brown trout

\begin{tabular}{|c|c|c|c|c|c|}
\hline Protein description & Accession number & Mass (Da) & Score & Matches & Coverage $(\%)$ \\
\hline Hornerin precursor & gi|40795897 & 283111 & 239 & 9 & 7 \\
\hline Serpin B12 & gi|17998551 & 46646 & 156 & 10 & 6 \\
\hline Annexin A2 isoform 2 & gi|4757756 & 38808 & 214 & 9 & 6 \\
\hline Glyceraldehyde-3-phosphate dehydrogenase & gi|31645 & 36202 & 179 & 7 & 4 \\
\hline High choriolytic enzyme 1 precursor & gi|225705620 & 32596 & 85 & 3 & 2 \\
\hline Fatty acid-binding protein & gi|4557581 & 15497 & 187 & 10 & 4 \\
\hline
\end{tabular}


Table 3 Unique proteins identified in the kidneys of brown trout

\begin{tabular}{|c|c|c|c|c|c|}
\hline Protein description & Accession number & Mass (Da) & Score & Matches & Coverage $(\%)$ \\
\hline \multicolumn{6}{|c|}{24 proteins identified in the kidneys of brown trout infected with Tetracapsuloides bryosalmonae } \\
\hline Epiplakin & gi|478538034 & 285127 & 77 & 3 & 2 \\
\hline Uncharacterized protein LOC101044508 & gi|403308699 & 148282 & 262 & 14 & 7 \\
\hline Protein NLRC3-like & gi|348522660 & 82990 & 63 & 3 & 2 \\
\hline Band-6-protein & gi|535015 & 81637 & 227 & 10 & 6 \\
\hline Transglutaminase E3 & gi|307504 & 77121 & 122 & 4 & 3 \\
\hline 11S globulin-like protein & gi|18479082 & 59605 & 372 & 20 & 8 \\
\hline Xaa-Pro aminopeptidase & gi|488783751 & 53714 & 63 & 3 & 2 \\
\hline Uncharacterized protein LOC678611 & gi|94536645 & 51128 & 327 & 31 & 7 \\
\hline Major facilitator transporter & gi|493287502 & 51089 & 62 & 2 & 2 \\
\hline Squamous cell carcinoma antigen & gi|239552 & 44564 & 93 & 5 & 3 \\
\hline Hypothetical protein BRAFLDRAFT & gi|260785919 & 42116 & 173 & 9 & 6 \\
\hline Hypothetical protein PANDA_012410 & gi|281341802 & 29722 & 262 & 34 & 5 \\
\hline 14-3-3 protein & gi|46326988 & 29216 & 62 & 2 & 2 \\
\hline Histone H2A-like & gi|528484029 & 27184 & 219 & 12 & 6 \\
\hline Trypsin 10 precursor & gi| 84781771 & 26888 & 63 & 3 & 2 \\
\hline Protease, serine, 1 precursor & gi|16716569 & 26802 & 98 & 12 & 2 \\
\hline Unnamed protein product & gi|47225212 & 25650 & 223 & 10 & 6 \\
\hline Casein alphaS1 & gi|225632 & 24477 & 139 & 6 & 3 \\
\hline Peroxiredoxin-1 & gi|4505591 & 22324 & 86 & 4 & 2 \\
\hline Hemoglobin IV beta & gi|185135748 & 16243 & 111 & 4 & 3 \\
\hline Protein S100A9 & gi|4506773 & 13291 & 86 & 5 & 3 \\
\hline Small proline-rich protein & gi|33842 & 10363 & 110 & 6 & 4 \\
\hline Cationic trypsinogen & gi|1616766 & 9200 & 80 & 3 & 2 \\
\hline Annexin A1 & gi|4502101 & 3891 & 411 & 15 & 9 \\
\hline \multicolumn{6}{|c|}{4 proteins identified in the kidneys of non-infected brown trout } \\
\hline Myeloperoxidase precursor & gi|224613258 & 70130 & 97 & 4 & 3 \\
\hline Rhamnose-binding lectin STL1 & gi| 185134460 & 35198 & 120 & 3 & 1 \\
\hline Caspase-14 precursor & gi|6912286 & 27947 & 136 & 5 & 5 \\
\hline Dermcidin preproprotein & gi|16751921 & 11391 & 88 & 6 & 2 \\
\hline
\end{tabular}

important proteins and pathways involved in the proliferation of the disease. This data can be used to develop novel control methods for T. bryosalmonae, based on the proteins or pathways identified in this study using RNA interference

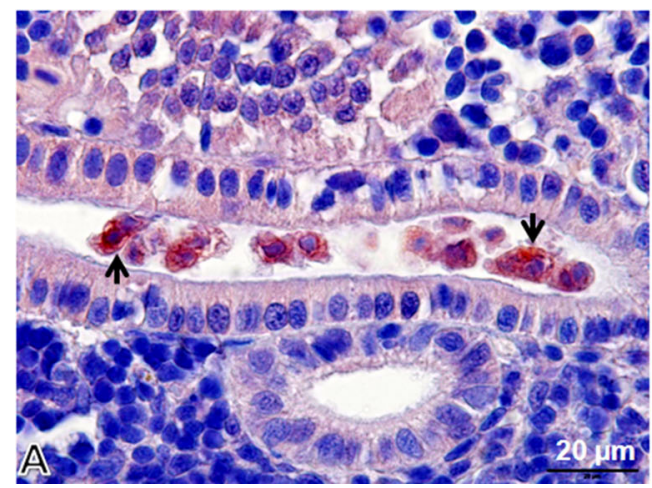

Fig. 2 Tetracapsuloides bryosalmonae stages in kidney tissues of brown trout, Salmo trutta. a Intra-luminal sporogonic stages of parasite (arrows) and proliferation of the interstitial tissue can be seen in the kidney of brown trout. Tubule lumen filled with numerous intra-luminal

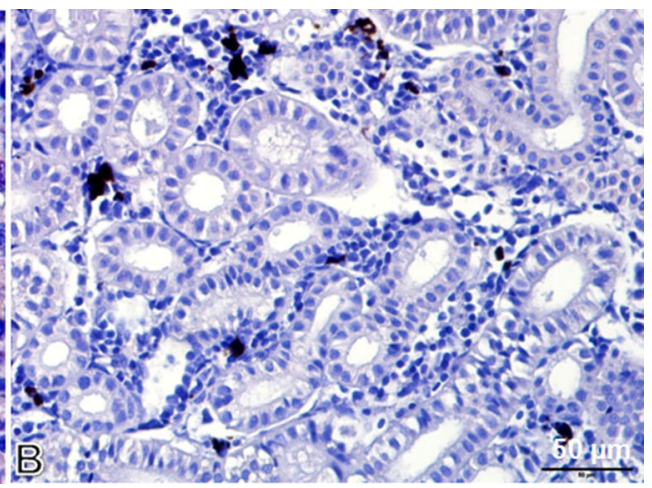

sporogonic stages of the parasite. b Non-infected kidney of brown trout. Parasite stages were visualized by immunohistochemistry using anti- $T$. bryosalmonae monoclonal antibody and counterstained with hematoxylin 
technology or other molecular based tools to differentially regulate genes implicated in PKD. Moreover, these proteins could be used for understanding the pathogenesis and defense mechanisms of other malacosporean species. Further research is needed to better understand how these proteins and their associated pathways are involved in the development of parasitic stages in the kidney of salmonids. Additionally, the identification in this study of so many different proteins clustered within a limited subset of functional pathways is in agreement with earlier reports of the promiscuous nature of protein interactions (Han et al. 2004; Agarwal et al. 2010). The results of this study open the door for identifying gene targets important for PKD and should be validated by other methods, such as yeast two-hybrid screening or fluorescently labeled protein microscopy and microarray analysis.

Acknowledgments This study was funded by the Austrian Science Fund (FWF) project number P 22770-B17. We would also like to thank the Proteomics Core Facility of the German Cancer Research Centre, Heidelberg, Germany, for its excellent work regarding protein identification by ESI-MS.

Conflict of interest The authors declare that they have no conflict of interests.

Open Access This article is distributed under the terms of the Creative Commons Attribution License which permits any use, distribution, and reproduction in any medium, provided the original author(s) and the source are credited.

\section{References}

Agarwal S, Deane CM, Porter MA, Jones NS (2010) Revisiting date and party hubs: novel approaches to role assignment in protein interaction networks. PLoS Comput Biol 6:e1000817

Anderson CL, Canning EU, Okamura B (1999) Molecular data implicate bryozoans as hosts for PKX (Phylum Myxozoa) and identify a clade of bryozoan parasites within the Myxozoa. Parasitology 119:555561

Baer BW, Rhodes D (1983) Eukaryotic RNA polymerase II binds to nucleosome cores from transcribed genes. Nature 5900:482-488

Cameron LC (2012) Mass Spectrometry Imaging: facts and perspectives from a non-mass spectrometrist point of view. Methods 57:417-422

Clifton-Hadley RS, Feist SW (1989) Proliferative kidney disease in brown trout Salmo trutta: further evidence of a myxosporean aetiology. Dis Aquat Org 6:99-103

Conti BJ, Davis BK, Zhang J, O'Connor W Jr, Williams KL, Ting JP (2005) CATERPILLER 16.2 (CLR16.2), a novel NBD/LRR family member that negatively regulates T cell function. J Biol Chem 280: $18375-18385$

Croce K, Gao H, Wang Y, Mooroka T, Sakuma M, Shi C, Sukhova GK, Packard RR, Hogg N, Libby P, Simon DI (2009) MRP-8/14 is critical for the biological response to vascular injury. Circulation 120: $427-436$

Davey GC, Calduch-Giner JA, Houeix B, Talbot A, Ariadna SitjàBobadilla A, Prunetd P, Pérez-Sánchezb J, Cairnsa MT (2011) Molecular profiling of the gilthead sea bream (Sparus aurata L.) response to chronic exposure to the myxosporean parasite Enteromyxum leei. Mol Immunol 48:2102-2112
El-Matbouli M, Hoffmann RW (2002) Influence of water quality on the outbreak of proliferative kidney disease-field studies and exposure experiments. J Fish Dis 25:459-467

Fujiwara S, Takeo N, Otani Y, Parry DA, Kunimatsu M, Lu R, Sasaki M, Matsuo N, Khaleduzzaman M, Yoshioka H (2001) Epiplakin, a novel member of the Plakin family originally identified as a 450 $\mathrm{kDa}$ human epidermal autoantigen. Structure and tissue localization. J Biol Chem 276:13340-13347

Gorgoglione B, Wang T, Secombes CJ, Holland JW (2013) Immune gene expression profiling of proliferative kidney disease in rainbow trout Oncorhynchus mykiss reveals a dominance of anti-inflammatory, antibody and $\mathrm{T}$ helper cell-like activities. Vet Res 44:55

Gotesman M, Hosein RE, Gavin RH (2011) MyTH4 and FERM have distinct roles that are essential for the function of a class XIV myosin in Tetrahymena thermophila. Cytoskeleton 68:220-236

Gotesman M, Soliman H, El-Matbouli M (2013) Antibody screening identifies 78 putative host proteins involved in Cyprinid herpesvirus 3 infection or propagation in common carp, Cyprinus carpio L. J Fish Dis 36:721-733

Grabner DS, El-Matbouli M (2008) Transmission of Tetracapsuloides bryosalmonae (Myxozoa: Malacosporea) to Fredericella sultana (Bryozoa: Phylactolaemata) by various fish species. Dis Aquat Org 79:133-139

Han JDJ, Bertin N, Hao T, Goldberg DS, Berriz GF, Zhang LV, Vidal M (2004) Evidence for dynamically organized modularity in the yeast protein-protein interaction network. Nature 430:88-93

Ho CS, Lam CW, Chan MH, Cheung RC, Law LK, Lit LC, Ng KF, Suen MW, Tai HL (2003) Electrospray ionisation mass spectrometry: principles and clinical applications. Clin Biochem Rev 24:3-12

Kumar G, Abd-Elfattah A, Saleh M, El-Matbouli M (2013) Fate of Tetracapsuloides bryosalmonae (Myxozoa) after infection of brown trout Salmo trutta and rainbow trout Oncorhynchus mykiss. Dis Aquat Org 107:9-18

Kumar G, Abd-Elfattah A, El-Matbouli M (2014) Differential modulation of host genes in the kidney of brown trout Salmo trutta during sporogenesis of Tetracapsuloides bryosalmonae (Myxozoa). Vet Res 45:101

Kumar G, Abd-Elfattah A, El-Matbouli M (2015) Identification of differentially expressed genes of brown trout (Salmo trutta) and rainbow trout (Oncorhynchus mykiss) in response to Tetracapsuloides bryosalmonae (Myxozoa). Parasitol Res. doi:10.1007/s00436-0144258-1

Marin de Mateo M, George J, Morris D, Kent ML (1996) Comparative studies of PKX and Sphaerospora spp. from salmonids using lectin and monoclonal antibody staining techniques. J Fish Dis 19:55-65

McMorrow T, Wagner A, Deryckere F, Gannon F (1996) Structural organization and sequence analysis of the globin locus in Atlantic salmon. DNA Cell Biol 15:407-414

Morris DJ, Adams A (2006) Transmission of Tetracapsuloides bryosalmonae (Myxozoa: Malacosporea), the causative organism of salmonid proliferative kidney disease, to the freshwater bryozoan Fredericella sultana. Parasitology 133:701-709

Morris DJ, Adams A (2007) Sacculogenesis and sporogony of Tetracapsuloides bryosalmonae (Myxozoa: Malacosporea) within the bryozoan host Fredericella sultana (Bryozoa: Phylactolaemata). Parasitol Res 100:983-992

Morris DJ, El-Matbouli M, Adams A (2004) Extensive release of an antigen associated with the sporogonic stages of Myxobolus cerebralis (Myxozoa: Myxosporea) is detected by a heterologous antibody raised to Tetracapsuloides bryosalmonae (Myxozoa: Malacosporea). Folia Parasitol 51:215-220

Ou X, Ji C, Han X, Zhao X, Li X, Mao Y, Wong LL, Bartlam M, Rao Z (2006) Crystal structures of human glycerol 3-phosphate dehydrogenase 1 (GPD1). J Mol Biol 357:858-869

Ouyang P, Rakus K, Boutier M, Reschner A, Leroy B, Ronsmans M, Fournier G, Scohy S, Costes B, Wattiez R, Vanderplasschen A 
(2013) The IL-10 homologue encoded by cyprinid herpesvirus 3 is essential neither for viral replication in vitro nor for virulence in vivo. Vet Res 44:53

Tatton W, Chalmers-Redman R, Tatton N (2003) Neuroprotection by deprenyl and other propargylamines: glyceraldehyde-3-phosphate dehydrogenase rather than monoamine oxidase B. J Neural Transm 110:509-515

Tuxworth RI, Stephens S, Ryan ZC, Titus MA (2005) Identification of a myosin VII-talin complex. J Biol Chem 28:26557-26564
Wahli T, Knuessel R, Bernet D, Segner H, Pugovkin D, Burkhardt-Holm P, Escher M, Schmidt-Posthaus H (2002) Proliferative kidney disease in Switzerland: current state of knowledge. J Fish Dis 25:491-500

Williams NE (2000) Immunoprecipitation procedures. In: Asai DJ, Forney JD (eds) Methods in cell biology: Tetrahymena thermophila. Academic, New York

Yasumasu S, Luchi I, Yamagami K (1989) Purification and partial characterization of high choriolytic enzyme (HCE), a component of the hatching enzyme of the Teleost, Oryzias latipes. J Biochem 105: 204-211 